\title{
Clinical, microbiological research of the effectiveness of inhalation use of quaternary ammonium antiseptic in the prevention and treatment of infectious respiratory complications in critically ill patients
}

\author{
Oleksandr A. Nazarchuk ${ }^{1 \oplus}$, Dmytro V. Dmytriiev ${ }^{2, *(}$, Kostiantyn D. Dmytriiev $^{3}{ }^{\circledR}$
}

${ }^{1}$ Department of Microbiology, Vinnytsya National Pirogov Memorial Medical University, str. Pirogova 56, 21018, Vinnytsia, Ukraine

${ }^{2}$ Department of Anesthesiology and Intensive Care, Vinnytsya National Pirogov Memorial Medical University, Vinnytsya, str. Pirogova 56, 21018, Vinnytsia, Ukraine

${ }^{3}$ Deparment of Propedeutics of Internal Medicine, Vinnytsya National Pirogov Memorial Medical University, str. Pirogova 56, 21018, Vinnytsia, Ukraine

\section{Correspondence}

Dmytro V. Dmytriiev, Department of Anesthesiology and Intensive Care, Vinnytsya National Pirogov Memorial Medical University, Vinnytsya, str. Pirogova 56, 21018, Vinnytsia, Ukraine

Email: dmytrodmytriiev@gmail.com

\section{History}

- Received: 16 September 2018

- Accepted: 05 November 2018

- Published: 08 December 2018

DOI :

https://doi.org/10.15419/bmrat.v5i12.504

\section{Check for updates}

\section{Copyright}

( ) Biomedpress. This is an openaccess article distributed under the terms of the Creative Commons Attribution 4.0 International license.

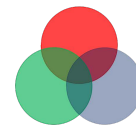

BioMedPress

The Open Access Publisher

\begin{abstract}
Introduction: The aim is to study the microbiological and clinical efficacy of decamethoxinebased quaternary ammonium antiseptic inhalations in the complex management of respiratory infectious complications in critically ill children. Methods: The use of inhalation of antiseptic medicinal decamethoxine (DCM) was studied in patients with ventilator-associated pneumonia (VAP) ( $n=30)$, of ages 12-18 years. All patients received standard intensive care according to the guidelines. Inhalations of $5 \mathrm{~mL}$ DCM (0.02\%) antiseptic per inhalation TID for 7 days in combination with systemic antibiotic therapy were used in the study group $(n=15)$. Clinical microbiological studies and assessment of Toll-like receptor (e.g. TLR-4) serum levels were performed in patients. Results: The use of DCM inhalations along with systemic antibiotic therapy improved parameters of dynamic compliance by 3.4-fold and decreased lung resistance by 2.4 -fold in patients after 48-72 hours of mechanical ventilation. The microbial spectrum of patients at the beginning of VAP was represented by gram-positive (S. aureus - 28.6\%, S. pyogenes - 10.2\%) and gramnegative (P. aeruginosa - 16.3\%; A. baumannii - 12.24\%; K. pneumoniae - 10.2\%) pathogens. The pathogens were isolated in the monoculture (20.4\%) and in microbial associations (79.6\%). A significant decrease by 3 orders of magnitude ( $\log (2.64 \pm 0.43)$ CFU/mL) in the microbial count in tracheobronchial secretions was determined after 7 days of additional use of DCM inhalations when compared to the initial levels of microbial colonization $(p<0.001)$. The microbial spectrum of the respiratory tract was predominantly represented by S. aureus (27.78\%), A. baumannii (11.11\%) and E. cloacae $(5.56 \%)$ in monoculture $(61.11 \%)$, whereas the microbial count was 4 orders of magnitude higher in the comparison group, versus that of the study group $(p<0.001)$, and was represented by microbial associations (93.33\%). A strong correlation was found between the reduction of the gram-negative pathogen count and the decrease of TLR-4 serum levels ( $r$-Pearson=0.893), that almost reached baseline levels after DCM inhalations, while TLR-4 levels remained 2 times higher than baseline levels after the use of systemic antimicrobial therapy alone $(p<0.001)$. Conclusion: The use of DCM inhalations in combination with systemic antibiotic therapy provides for an effective reduction of pathogen count in the respiratory tract, leading to the early (48-72h) improvement in lung ventilation and TLR-4 serum levels, and subsequent significant improvement of treatment efficacy in severe VAP patients.
\end{abstract}

Key words: Antiseptics, Decamethoxine, Respiratory infection, VAP

\section{INTRODUCTION}

Respiratory infections in critically ill patients are associated with threatening factors, which significantly impair course of the main pathology, make treatment more complicated and increase treatment cost, and increase mortality of the affected patients. Pneumonia is one of the most frequent (6-52\%) and serious hospital-acquired infectious complications which occur in critically ill children, and which is treated in the intensive care unit (ICU) ${ }^{1-5}$. Pneumonia is diagnosed in 9-10 cases per 1000 of all hospitalized critically ill

\section{patients $^{1,6}$.}

According to the data of North American and European researchers, the incidence of ventilatorassociated pneumonia (VAP) in patients of multidisciplinary ICU reaches $23.8-32.0 \%{ }^{5}$. Patients on mechanical ventilation (MV) belong to a special risk group. The specified risk index of VAP is found in $30 \%$ of patients who undergo MV. According to the National Nosocomial Infection Surveillance (NNIS) system data, VAP can develop in 6 cases per 1000 patient ventilator days. Thus, the mortality rate in patients with VAP varies from $20-50 \%$, and in some
Cite this article : A. Nazarchuk O, V. Dmytriiev D, D. Dmytriiev K. Clinical, microbiological research of the effectiveness of inhalation use of quaternary ammonium antiseptic in the prevention and treatment of infectious respiratory complications in critically ill patients. Biomed. Res. Ther.; 5(12):2850-2862. 
cases, when the etiological factor of this complication is multidrug-resistant agents, may exceed $70 \%{ }^{1,2,5-8}$. The microbial factor is crucial in causing VA and influences the recovery of patients with this pathology. The current thought is that opportunistic pathogens, such as Pseudomonas aeruginosa, Enterobacteriaceae, Staphylococcus aureus, Candida albicans, have been postulated to frequently acquire multi-drug antimicrobial resistance $(17 \%)^{9}$.

According to scientifically substantiated recommendations, the main task of the prevention and treatment of ventilator-associated respiratory infections in critically ill patients is the rational administration of the antibiotic therapy in adequate doses. At the same time, avoiding de-escalation systemic antibiotic therapy, along with the obligatory consideration of microbiological confirmation of the etiology of the disease and the individual susceptibility of the patient in response to treatment, should be taken into account. Reducing the duration of systemic antibiotic therapy and ensuring a minimum effective period of treatment is a leading priority ${ }^{10-12}$.

Due to the imperfection of existing approaches to systemic antibiotic prevention and treatment of VAP, there is an urgent need for the improvement of current methods as well as alternative methods for controlling poly-resistant respiratory tract infection. Besides well-known standard approaches to antibacterial prevention and treatment, a number of advantages of inhalations of antimicrobial agent in the treatment of VAP have been established. According to data from some of these research studies, the use of inhalation is particularly justified in combination with systemic administration of antibiotics in the treatment of VAP caused by poly-resistant pathogens ${ }^{13}$.

Nowadays, the focus of research is on the complex use of antibiotics and antiseptics in the management of infectious complications due to the spread of antibiotic resistance in causative agents of respiratory complications. High antimicrobial properties, slow occurrence of resistance in pathogens, and low toxicity of antiseptics open up new prospects for their use in the fight against causative agents of VAP. There has been data on the effective reduction of risk of VAP development in children who have received oral and pharyngeal cleansing with chlorhexidine and povidone-iodine antiseptics prior to the intubation of the trachea ${ }^{14-18}$. Moreover, Ukrainian scientists have established the clinical efficacy of oral sanitation (before endotracheal intubation) with decamethoxine-based antiseptic remedy Decasan, which belongs to the family of quaternary ammonium compounds (QACs), in the prevention of respiratory complications in adults and children patients at the ICU ${ }^{19,20}$. Administration of Decasan was by means of oral sanitation (before endotracheal intubation) ${ }^{19,20}$.

The successful experience and high efficacy of the inhalatory use of Decasan in the treatment and prevention of infectious complications among patients with chronic respiratory diseases (bronchial asthma, chronic obstructive pulmonary disease, etc.) have been demonstrated. The efficacy of Decasan use in inhalations, according to the results of this study, has led to greater scientific and practical interest in the development of new approaches to treating respiratory complications caused by poly-resistant pathogens in patients on long-term mechanical respiratory support $^{21}$.

The aim of this study was to study the microbiological, clinical efficacy of decamethoxine-based quaternary ammonium antiseptic inhalations in the complex management of respiratory infectious complications in critically ill children.

\section{METHODS}

\section{Study Design and Ethical Considerations}

A clinico-microbiological prospective, randomized, double-blind, placebo-controlled study of the efficacy of decamethoxine-based antiseptic drug use in inhalations in patients with respiratory infectious complications was conducted. A completed medical form of an antiseptic based on decamethoxine (1,10-Decamethylene bis $(\mathrm{N}$, $\mathrm{N}$-dimethylmethoxycarbonylmethyl) ammonium dichloride) was used; Decasan (which contains decamethoxine $200 \mu \mathrm{g} / \mathrm{ml}$ ), was produced by the pharmaceutical company Yuria-Pharm, LLC (Ukraine). Antiseptic remedy Decasan was re-registered in Ukraine on December 22, 2016 according to Order No. 1391 indefinitely (validity of the registration certificate number UA/5364/01/01 on the territory of Ukraine is unlimited). After approval from a research ethics committee, patients were enrolled in the research and were managed in the ICU of Vinnytsia Regional Clinical Hospital (Vinnytsia, Ukraine) from 2016-2017. This trial was conducted with the mandatory notification of the patients' parents and their written consent, according to the measures concerning the patients' health, observance of their rights, human dignity, and moral and ethical standards, as stipulated by the principles of the Helsinki Declaration of Human Rights, the Council of Europe Convention on Human Rights and Biomedicine, relevant laws, and orders of the Ministry of Health of Ukraine. 


\section{Patients and Inclusion Criteria}

30 patients who had undergone MV for 48 hours or more were enrolled in the study. Ventilatorassociated pneumonia was diagnosed according to the criteria of the US Centers for Disease Control and Prevention (CDC). According to these recommendations, the diagnosis of VAP was based on clinical symptoms, radiologic criteria and mandatory additional microbiological confirmation ${ }^{22,23}$. All examined patients were $12-18$ years old (the mean age in the study group was $14.6 \pm 1.96$ years in the comparison group the mean age was $15.3 \pm 1.87$ years). There were $16(53.3 \%)$ girls and 14 (46.7\%) boys.

Themain criteria for selecting patients for participation in this study were the following:

-Age of the patients (from 12 to 18 years) at the beginning of the study.

-Patients were on mechanical ventilation for $>48$ hours.

-Patients had a diagnosis of VAP, which was made on the basis of the following criteria:

+ clinical symptoms - acute onset, fever greater than $38.0^{\circ} \mathrm{C}$ for 3 days or hypothermia below 36.0 ${ }^{\circ} \mathrm{C}$, intoxication syndrome, discharge from the endotracheal tube, severe respiratory failure, tachycardia, and/or bradycardia;

+ auscultation - diminished vesicular respiration, crepitus or presence of crackles;

+ data of US investigation of the lungs - increased echogenicity of the lung tissue or presence of infiltration foci;

+ data of chest X-ray - infiltrative focal or segmental changes in the lungs;

+ reduction of oxygen saturation

+ laboratory research methods: complete blood count (leukocytosis with shift of the formula to the left, or leukopenia, accelerated erythrocyte sedimentation rate);

-Patient and his/her parents were willing and able to cooperate throughout the entire study.

-Patients in the observation group were additionally differentiated by the severity index, according to the criteria of "The point scoring system of pneumonia severity index in children ${ }^{24}$ ". According to this, the degree of disease manifestation was assessed based on clinical, laboratory and instrumental methods (Tables 1 and 2). According to the above mentioned scoring system, patients were classified as the following: $4^{\text {th }}$ degree (7 patients); $5^{\text {th }}$ degree (23 patients).

\section{Exclusion Criteria}

Criteria for exclusion of patients from the study were as follows:

-Female participant were ineligible to participate in the study if they were pregnant and/or breastfeeding. -Patients with acute kidney injury or chronic kidney disease accompanied by anuria or oliguria were not eligible to participate in the study.

-Patients who has comorbid pathologies (heart failure, diabetes mellitus or other acute conditions) were excluded; in the opinion of the Investigator, these pathologies could influence safety and results of the study

-Patients who were currently participating in another clinical study.

-Patients who were unable to provide consent for his/her participation in the trial (coma).

-One of the parents did not provide a consent for the child's participation in the clinical trial.

\section{Interventions and management}

All patients received standard, complex intensive management, according to the guidelines for treatment of the underlying pathology. Respiratory support was performed using a device "Hamillton-C2" in ASV mode $\left(\mathrm{FiO}_{2}, 30 \%\right.$, positive end-expiratory pressure (PEEP): $2 \mathrm{~cm} \mathrm{H}_{2} \mathrm{O}$, eak inspiratory pressure (PIP): $15-20 \mathrm{~cm} \mathrm{H}_{2} \mathrm{O}$ ), with the correction of parameter according to the dynamics of spontaneous breathing recovery, state of hemodynamics and oxygen saturation of the blood.

Patients in both groups received complex intensive care for the stabilization of the parameters of hemodynamics (volume, inotropic and vasopressor support), hemostasis, rheological parameters, acid-base balance and electrolyte levels, and provision of effective anesthesia and sedation.

All patients received systemic antibiotic therapy, which was empirically administered at the beginning of treatment according to the de-escalation principle of antimicrobial management, followed by correction according to the results of antibiotic susceptibility testing of the isolated VAP pathogens. Empirical antibiotic therapy was consistent with the generally accepted approaches of VAP treatment.

\section{Randomization}

All patients were divided into two groups: a DCM group and a comparison group ( $\mathrm{n}=15$ per group). $\mathrm{Pa}-$ tients of the study group received systemic antibiotic therapy according to clinical guidelines together with inhalations of decamethoxine from the first day 
Table 1: Point Scoring System of Pneumonia Severity Index

Clinical characteristics and demographics

Characteristics

Age: 3 - 15 years

Comorbidity

Congenital heart disease

Renal disease

Immunodeficiency

Impairment of consciousness

Cyanosis

Tachycardia

Score
+10

$+30$

$+10$

$+10$

$+20$

$+15$

$+10$
Laboratory features

$\begin{array}{lc}\text { Characteristics } & \text { Score } \\ \text { Leukocytosis } & +10 \\ \text { Leukopenia } & +20 \\ \text { Anemia } & +10 \\ \mathrm{pH}<7.35 & +30 \\ \mathrm{BUN}>11 \mathrm{mmol} / \mathrm{l} & +20 \\ \mathrm{Hct}<30 \% & +10 \\ \text { SaO2 }<90 \% & +20 \\ \text { Multilobar Infiltration on X-ray } & +15 \\ \text { Toxic shock syndrome } & +40 \\ \text { Pleural effusion } & +30 \\ \text { Destruction } & +50\end{array}$

Score

$+10$

$+20$

$+10$

$+30$

$+20$

$+10$

$+20$

$+15$

$+40$

$+30$

$+50$

Table 2: The Scale of Pneumonia Severity Index In Children

\begin{tabular}{|c|c|c|c|}
\hline Severity Index Degree & Scores & Mortality Risk (\%) & $\begin{array}{l}\text { Recommendations for the } \\
\text { place of medical assistance }\end{array}$ \\
\hline the $4^{t h}$ degree & $91-130$ & 8.2 & Hospital admission \\
\hline the $5^{t h}$ degree & $>130$ & 29.2 & Hospital admission \\
\hline
\end{tabular}

of VAP. Decamethoxine was administered as $5 \mathrm{ml}$ through a nebulizer TID (three times daily) for 7 days. Patients in the comparison group received systemic antibiotic therapy together with the inhalations of physiological solution in the same quantities and timing as patients in the main group. The nebulizer was connected at the inspiratory end at $15-20 \mathrm{~cm}$ higher than the special "Y-like" convector.

\section{Clinical assessment}

Treatment efficacy was assessed on the basis of dynamic of clinical parameters, mechanical ventilation parameters and its duration, and from information of microbiological analyses of the tracheobronchial secretions. Treatment efficacy for the study and comparison groups was assessed on the basis of general clinical parameters (body temperature, self-efficacy, and oxygen saturation), laboratory (WBC count in peripheral blood) and information of instrumental (chest X-ray) methods, as well as changes in parameters of respiratory function (dynamic compliance - C dyn, positive end-expiratory pressure - PEEP, peak inspiratory pressure - PIP). The research was carried out at the following stages: $1^{\text {st }}-$ at the beginning of $\mathrm{MV}, 2^{\text {nd }}$ - after 24 hours of MV, $3^{\text {rd }}$ - after 36 hours of MV, $4^{t h}-$ after 48 hours of MV, and $5^{t h}-$ after 72 hours of MV.

\section{Microbiological study}

Clinically significant pathogens of VAP were isolated and then identified according to their morphological, tinctorial, cultural and biochemical properties. Materials for the microbiological study was taken from the surface of endotracheal tubes during their scheduled change or on the indication to orotracheal intubation. If sanitary fibrobronchoscopy was performed, then bronchial washings were taken for the microbiological examinations. If patients returned back to spontaneous breathing, then sputum was used as a material for microbiological evaluation.

The initial microbiological study was performed prior to the administration of antibiotic therapy and then at 3,7 , or 14 days of treatment. Isolated microorganisms were finally identified according to their morphological, cultural and biochemical features using common methods. Biochemical properties of grampositive and gram-negative strains were identified by standardized test systems, such as STAPHY-test 24, ENTERO-test and NEFERM-test 24 (PLIVA Lachema a. s. Brno, Czech Republic). Final identi- 
fication was performed by the automatic bacteriological analyzer ViteK 2 Compact (BioMérieux, France). Quantitative analysis of microorganisms in the biological material was performed according to standard methods along with specific identification of the microorganisms.

The degree of general microbial colonization of the respiratory tract was estimated by the microbial count in $1 \mathrm{ml}$ of biological material, expressed as $\log$ $\mathrm{CFU} / \mathrm{ml}$, and conducted in a certified bacteriological laboratory of the Microbiology Department of National Pirogov Memorial Medical University, Vinnytsya.

\section{Assessment of immunological marker}

Serum levels of Toll-like receptors (TLR-4) were assessed as an additional parameter of treatment efficacy. TLR-4 is a signaling molecule of the nonspecific immune response of an organism to infections caused by gram-negative bacteria ${ }^{25}$. TLR- 4 serum levels were determined in patients on the $1^{\text {st }}$, $3^{r d}$, and $7^{\text {th }}$ days of treatment. Serum TLR-4 levels were determined using ELISA method according to the manufacturer's instructions for the Human TLR4 ELISA Kit (NeoBiolab, USA).

In brief, $100 \mu \mathrm{L}$ of standard solutions (concentrations of estradiol $0 ; 1.0 ; 2.5 ; 5.0 ; 10.0 ; 25.0 \mathrm{ng} / \mathrm{mL}$ ), $50 \mu \mathrm{L}$ of enzymatic conjugate (streptavidin-peroxidase) were added and mixed for 10 seconds into microliter plates with antibodies to estradiol adsorbed on them. Incubation of these covered wells was performed for 60 minutes in humid chamber $\left(37^{\circ} \mathrm{C}\right)$ for the formation of antibody-antigen-antibody-enzyme complexes.

Each well was then washed to remove no -conjugated reagents, then $50 \mu \mathrm{L}$ of chromogenic substrate were added to each well. The mixed wells were incubated for $15 \mathrm{~min}$ at $25^{\circ} \mathrm{C}$. After the reaction was stopped with addition of $50 \mu \mathrm{L}$ of top solution, the optical density (O.D.) at $450 \mathrm{~nm}$ was immediately obtained (differential filter was at $630 \mathrm{~nm}$ ), using testing technique STAT FAX 303/PLUS.

Samples of serum were conserved at $20^{\circ} \mathrm{C}$ below zero in Eppendorf microtubes before testing. All samples were in good condition for the study prior to testing. There were no hemolyzed samples with blood rolls or lipemic serum; thus, all samples were in good condition prior to the testing. The analyses of the biological material were carried out in the Scientific and Clinical laboratory of the Department of biological and General Chemistry of Vinnytsya National Pirogov Memorial Medical University (Attestation science license 02.03.2015) per the order of the Ministry of Health of Ukraine (№ 049/15).
Analysis of the obtained data was performed in Microsoft Excel 2016 and Statistica 5.5. Statistic variation analysis methods were used. The statistical significance of the obtained data was analyzed according to the student's t-test. The r-Pearson criterion was determined for the assessment of relationship between parameters. Difference between the indicators were considered statistically significant if the probability of fairness of the null hypothesis was less than $5 \%(\mathrm{p}<0.05)$.

\section{RESULTS}

\section{Respiratory monitoring}

Gradual decrease, by 3.4-fold, of dynamic compliance was detected after 48 hours for the comparison group, while in the main study group there were no such changes in the dynamic compliance (Table 3 ).

An increase of resistance (by 2.4-fold) and significant increase in PIP values (20-22 cm water column) were determined in patients of the comparison group. Maximum changes of the parameters on the graphic screen were also established in this group. These changes were accompanied by prolonged purulentinflammatory process in the lungs, which was possibly caused by the lack of efficacy of antimicrobial therapy or as a result of the persistence of resistant microorganisms, in comparison with patients who received additional nebulization with DCM in the early VAP period (Table 3).

\section{Etiology of VAP and microbiological charac- teristics}

From the results of the microbiological evaluation of the 30 samples of biological material, which were received from VAP patients $(n=30)$ at the early period of the disease, 49 strains of opportunistic microorganisms were isolated and identified by their morphological, tinctorial and biochemical properties (Figure 1). In patients with VAP at the onset of the disease, the microbial spectrum of pathogens was predominantly represented by gram-positive (S.aureus $28.6 \%$, S.pyogenes - 10.2\%), and gram-negative (P.aeruginosa - 16.3\%; A.baumannii - 12.24\%; K.pneumoniae - 10.2\%) bacteria. Yeast-like fungi of the genus Candida were found in less quantity (10.2\%). Opportunistic pathogenic microorganisms were isolated from the respiratory tract through the endotracheal tube in monoculture (20.4\%) and in microbial associations (79.6\%) before the initiation of antimicrobial therapy (Figure 2).

The clinical strains of opportunistic gram-positive microorganisms S.pyogenes, S.epidermidis, Kocuria spp., 


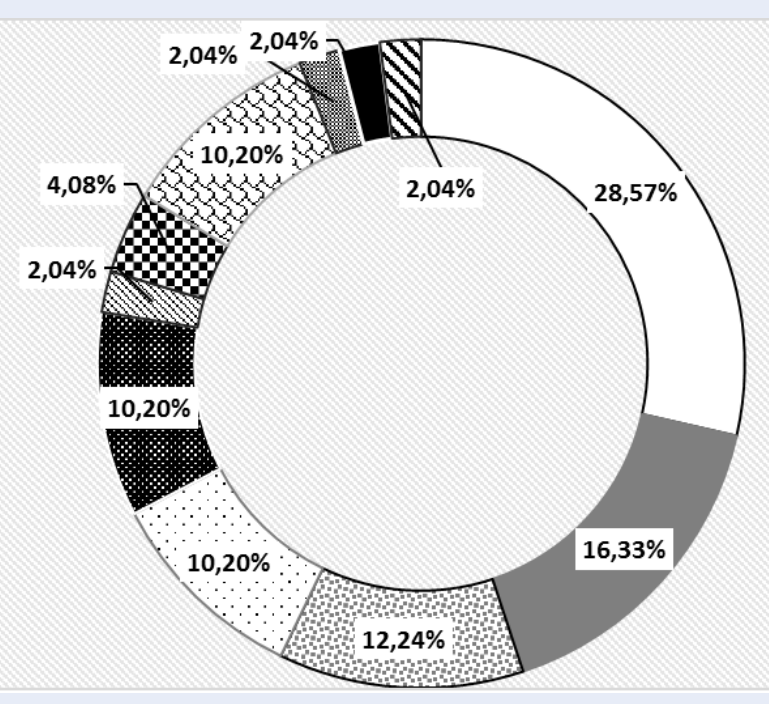

$\square$ S.aureus

P.aeruginosa

용 A.baumannii

$\checkmark$ S.pyogenes

K.pneumoniae

国. aerogenes

由 Kocuria spp.

Q.albicans

E. cloacae

- S.epidermidis

⿶S. maltophilia

Figure 1: Structure of pathogens from the total number of microbial strains at the treatment initiation. Quantitative value of opportunistic microbial strains, that have colonized airways in patients with VAP in both groups before the treatment initiation.

Q observation group monoculture

$\sqcap$ comparlson group monoculture $\square$ observation group association of microorganisms

- comparlson group assoclatlon of microorganlsms

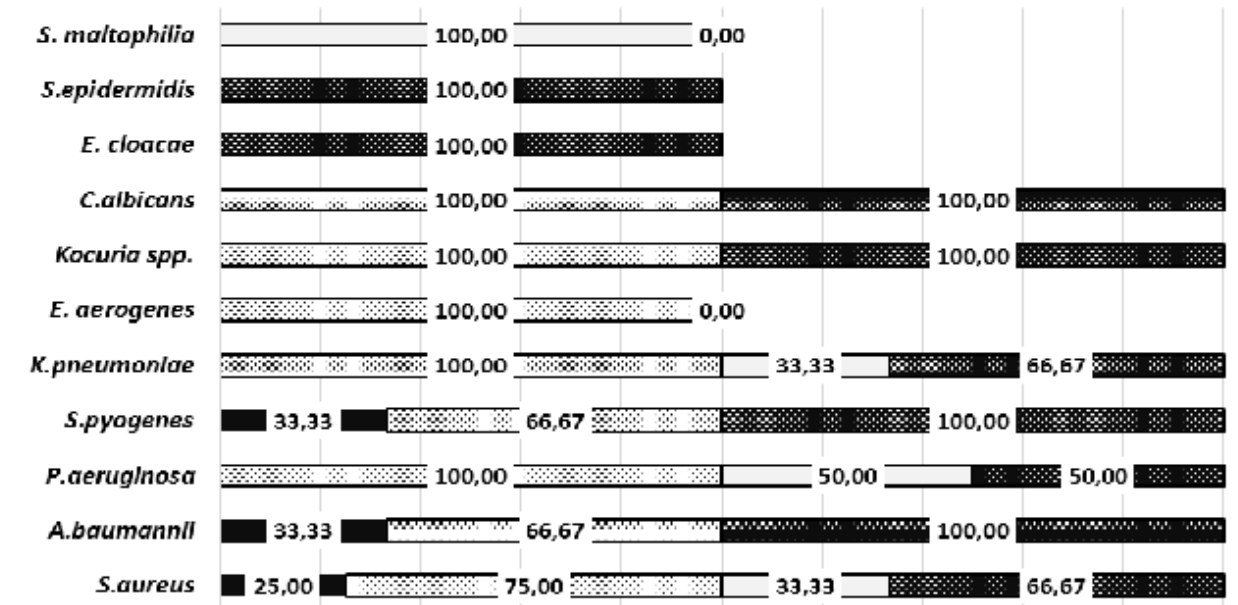

Figure 2: Occurrence in monoculture and microbial associations in patients with VAP before treatment. Qualitative and quantitative distribution of identified microbial strains according to incidence of monocultures and microbial associations inpatients with VAP before the initiation of antimicrobial therapy. 


\begin{tabular}{|c|c|c|c|c|c|}
\hline Parameter & $\begin{array}{c}\text { At the } \\
\text { beginning of } \\
\text { MV }\end{array}$ & $\begin{array}{c}\text { After } \\
24 \text { hours of MV }\end{array}$ & $\begin{array}{c}\text { After } \\
36 \text { hours of } \\
\text { MV }\end{array}$ & $\begin{array}{l}\text { After } \\
48 \text { hours of } \\
\text { MV }\end{array}$ & $\begin{array}{c}\text { After } \\
72 \text { hours of } M V\end{array}$ \\
\hline \multicolumn{6}{|c|}{ Group of patients without using decamethoxin (comparison group), $\mathrm{n}=15$} \\
\hline $\begin{array}{l}\mathrm{C} \text { dyn } \\
\left(\mathrm{mL} / \mathrm{cm} \mathrm{H}_{2} \mathrm{O}\right)\end{array}$ & $3.81 \pm 0.2$ & $1.12 \pm 0.1^{*}$ & $1.38 \pm 0.3^{*}$ & $2.23 \pm 0.1^{*}$ & $4.01 \pm 0.2$ \\
\hline $\begin{array}{l}\mathrm{C} \text { dyn } / \mathrm{kg} \\
\left(\mathrm{mL} / \mathrm{cm} \mathrm{H}_{2} \mathrm{O} / \mathrm{kg}\right)\end{array}$ & $1.06 \pm 0.1$ & $0.87 \pm 0.2$ & $0.96 \pm 0.1$ & $0.98 \pm 0.1$ & $1.04 \pm 0.1$ \\
\hline $\mathrm{C} 20 / \mathrm{C}$ & $3.26 \pm 0.1$ & $2.24 \pm 0.8^{*}$ & $2.44 \pm 0.7^{*}$ & $2.87 \pm 1.3^{*}$ & $3.42 \pm 0.9$ \\
\hline $\begin{array}{l}\text { Rpk } \\
\left(\mathrm{cm} \mathrm{H}{ }_{2} \mathrm{O} / \mathrm{L} / \mathrm{kg}\right)\end{array}$ & $189.0 \pm 9.1$ & $401.0 \pm 9.0^{*}$ & $280.0 \pm 9.1^{*}$ & $202.0 \pm 7.4$ & $198.0 \pm 8.0$ \\
\hline $\begin{array}{l}\text { PIP } \\
\left(\mathrm{cm} \mathrm{H}{ }_{2} \mathrm{O}\right)\end{array}$ & $12.4 \pm 1.8$ & $14.6 \pm 2.4^{*}$ & $21.2 \pm 2.2^{*}$ & $18.6 \pm 1.9$ & $14.0 \pm 2.0$ \\
\hline $\begin{array}{l}\text { PEEP } \\
\left(\mathrm{cm} \mathrm{H}_{2} \mathrm{O}\right)\end{array}$ & $3.0 \pm 0.06$ & $5.2 \pm 0.04^{*}$ & $4.9 \pm 0.08$ & $5.0 \pm 0.08^{*}$ & $2.4 \pm 0.08$ \\
\hline \multicolumn{6}{|c|}{ Group of patients using decamethoxin (main study group), $n=15$} \\
\hline $\begin{array}{l}\text { C dyn } \\
\left(\mathrm{mL} / \mathrm{cm} \mathrm{H} \mathrm{H}_{2} \mathrm{O}\right)\end{array}$ & $4.02 \pm 0.1$ & $4.03 \pm 0.2$ & $4.06 \pm 0.2$ & $4.02 \pm 0.3$ & $4.02 \pm 0.2$ \\
\hline $\begin{array}{l}\mathrm{C} \text { dyn } / \mathrm{kg} \\
\left(\mathrm{mL} / \mathrm{cm} \mathrm{H}_{2} \mathrm{O} / \mathrm{kg}\right)\end{array}$ & $1.14 \pm 0.3$ & $1.08 \pm 0.4$ & $1.09 \pm 0.2$ & $1.11 \pm 0.4$ & $1.12 \pm 0.6$ \\
\hline $\mathrm{C} 20 / \mathrm{C}$ & $3.68 \pm 0.6$ & $3.49 \pm 0.8$ & $3.62 \pm 0.4$ & $3.70 \pm 0.8$ & $3.68 \pm 0.6$ \\
\hline $\begin{array}{l}\text { Rpk } \\
\left(\mathrm{cm} \mathrm{H} \mathrm{H}_{2} \mathrm{O} / \mathrm{L} / \mathrm{kg}\right)\end{array}$ & $208.0 \pm 9.6$ & $209.0 \pm 10.0$ & $208.7 \pm 9.6$ & $211.2 \pm 8.6$ & $206.8 \pm 8.2$ \\
\hline $\begin{array}{l}\text { PIP } \\
\left(\mathrm{cm} \mathrm{H}{ }_{2} \mathrm{O}\right)\end{array}$ & $11.9 \pm 2.0$ & $12.2 \pm 1.8$ & $12.0 \pm 2.4$ & $13.4 \pm 2.3$ & $12.0 \pm 2.2$ \\
\hline $\begin{array}{l}\text { PEEP } \\
\left(\mathrm{cm} \mathrm{H}{ }_{2} \mathrm{O}\right)\end{array}$ & $3.1 \pm 0.04$ & $2.2 \pm 0.04$ & $2.4 \pm 0.04$ & $2.6 \pm 0.04$ & $2.2 \pm 0.08$ \\
\hline
\end{tabular}

Note: ${ }^{*}<0.05$ when comparing patients in two groups

and gram-negative representatives of genus Enterobacter were isolated in association with other bacteria and yeast-like fungi of the genus Candida. In the vast majority of cases, Klebsiella and non-fermenting gram-negative bacteria (A.baumannii, P.aeruginosa) were isolated from patients as part of microbial associations. According to the results of the observation of patients with VAP, qualitative changes in the conditional pathogenic microflora of the respiratory tract during treatment were seen.

On the $3^{r d}$ day after treatment initiation in both groups, the predominance of microbial associations in the sputum of patients was noted (study group 85.2\%; comparison group - 87.1\%), in comparison with isolated pathogens in monoculture (study group $-14.8 \%$; comparison group - 12.9\%). However, significant differences were found between the composition of stains in the two groups of patients. In patients who received additional inhalation therapy with Decasan for 3 days, S.aureus (29.63\%) and P.Aeruginosa (22.22\%) were found as leading isolates from the tracheobronchial tract. S.pyogenes and C.albicans were also isolated (11.11\% in each case). The presence of A.Baumannii and K.pneumoniae (7.41\% each) were rarely observed. In the comparison group, Pseudomonas aeruginosa prevailed (22.58\%). Furthermore, S. aureus was determined only in $19.35 \%$ of cases. Also, Acinetobacteria and Klebsiella were isolated from patients in the comparison group (12.9\%), which were somewhat more frequent than in the main group. Candida spp. were registered within the 3 days as part of the microbial associations in $9.68 \%$ of cases. The incidence of other types of gram-positive and gram-negative bacteria was negligible in both groups (3.23-3.7\%) (Figure 3). 


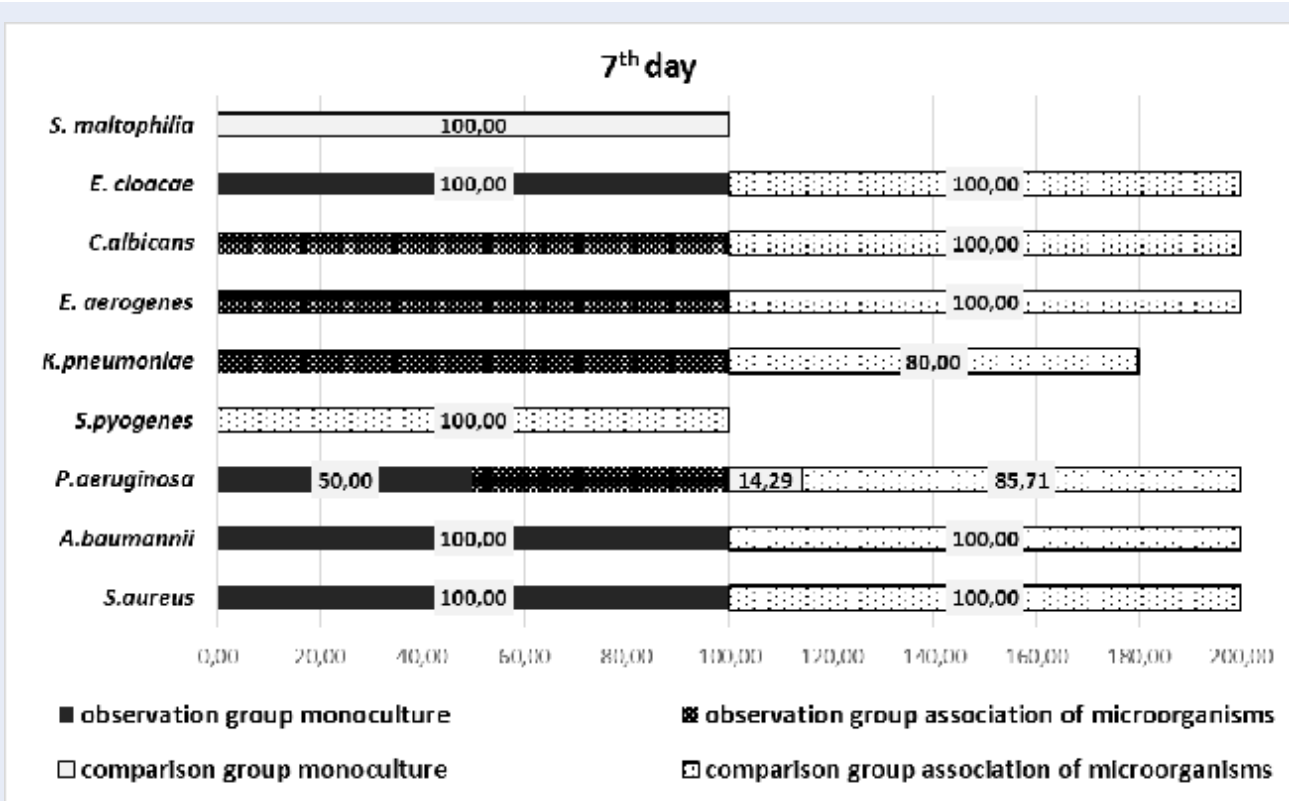

Figure 3: Occurrence in monoculture and microbial associations in patients with VAP at the $7^{\text {th }}$ treatment day. Qualitative and quantitative distribution of identified microbial strains according to incidence of monocultures and microbial associations in patients with VAP after seven days of antimicrobial therapy.

After the $7^{\text {th }}$ day of observation of the group of patients who received additional inhalation administration of DCM, it was noted that within the tracheobronchial tract were S.aureus (27.78\%), A.baumannii (11.11\%) and E.cloacae (5.56\%), which were predominantly in monoculture $(61.11 \%)$. These pathogens were isolated from 11 patients. Associations of gramnegative bacteria were determined (P.aeruginosa $33.33 \%$; K.pneumoniae - 5.56\%; E.aerogenes $5.56 \%)$, as well as C.albicans (11.11\%) in the tracheobronchial aspirate of the 4 cases of the same group (Figure 3).

P.aeruginosa (a pathogen of airway infections) was found in monoculture only in 1 patient in the comparison group. The $7^{t h}$ day microflora of the respiratory tract was represented mainly by associations of microorganism in 14 (93.33\%) patients with VAP; this consisted of $89.29 \%$ of all isolated microorganisms in the comparison group.

On the $14^{t h}$ day, in the sputum of 5 seriously ill patients, the main pathogens of infectious complications that were identified were the following: in 1 case, S.Aureuswas found (its quantity did not exceed $\log 2$ $\mathrm{CFU} / \mathrm{ml}$ ); A.baumannii was also found in 1 of the patients (who had a significant regression of the clinical disease); and in 3 patients, a small number of $P$. aeruginosa was found $(\log 3-6 \mathrm{CFU} / \mathrm{mL})$.
Microbiological examinations of the biological materials received from the airway of patients demonstrated that at the beginning of treatment, the average values of the number of microorganisms were conditionally expressed in log; the results for the main group $(6.73 \pm 0.32 \mathrm{CFU} / \mathrm{mL})$ did not differ significantly from the level of microbial colonization in the respiratory tract of patients in the comparison group $(5.86 \pm 0.28 \mathrm{CFU} / \mathrm{mL} ; \mathrm{p}>0.05)$. During treatment, there was a microbiologically determined gradual decrease in the quantitative content of microorganisms in the samples obtained from the patients in both groups. In the group of patients who received inhalation administration of DCM, a significant decrease in microbial colonization was observed, starting from the $3^{\text {rd }}$ day of treatment $(\log (5.49 \pm 0.27$ $\mathrm{CFU} / \mathrm{mL}$ ) (Figure 4).

Microbial colonization of the respiratory tract of patients in the comparison group on the $3^{r d}$ day of treatment was $1.1 \mathrm{log}$ higher, indicating 14 -fold increase in the absolute amount of microorganisms in the sputum from the respiratory tract of the patients in the comparison group $(\mathrm{p}<0.001)$. A significant reduction of the microbial count in the tracheobronchial secretions, by 3 orders of magnitude $(\log (2.64 \pm 0.43)$ $\mathrm{CFU} / \mathrm{mL}$ ), were found in patients after decamethoxine use, as compared to the baseline microbial colonization $(\mathrm{p}<0.001)$, which in absolute amount corresponded to their decrease in CFU per $1 \mathrm{~mL}$ of $10^{4}$ 


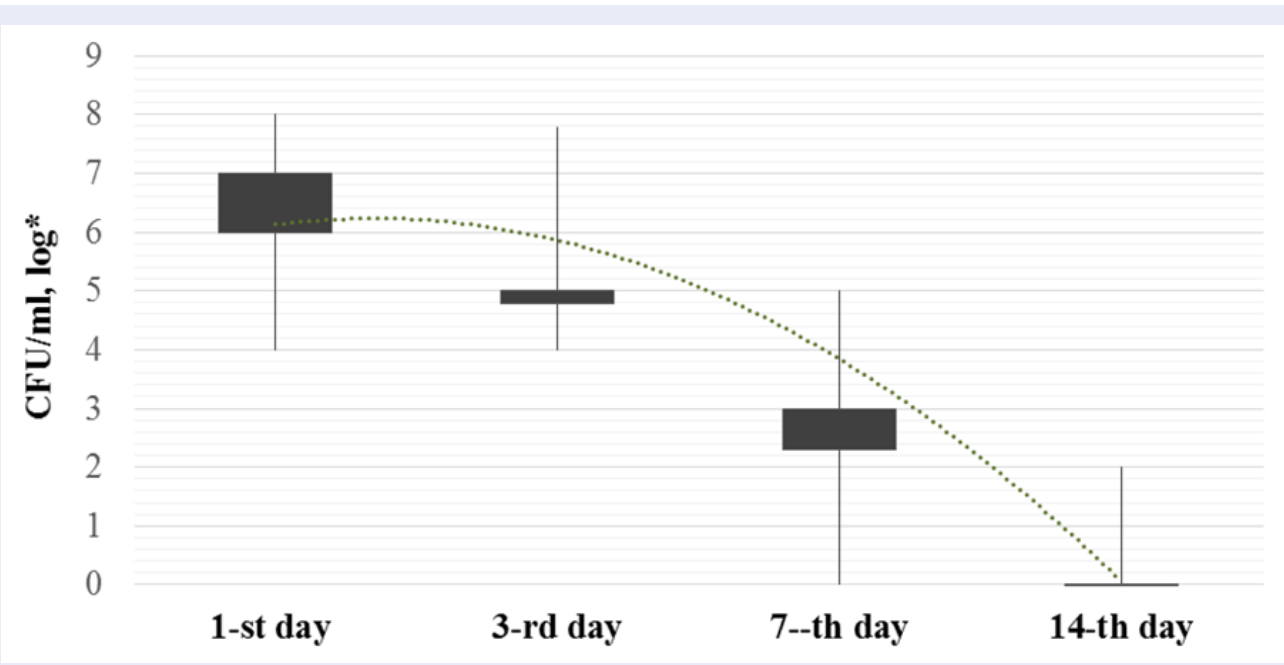

Figure 4: Microbial colonization rate of airways in patients with combined use of DCM with antibiotic therapy. *: average values of the total number of microorganisms in $1 \mathrm{~mL}$ of tracheobronchial aspirates are expressed in log (CFU/mL). Average number of microorganisms in $1 \mathrm{~mL}$ of tracheobronchial aspirates expressed in $\log (\mathrm{CFU} / \mathrm{mL}$ ) from the beginning of antimicrobial therapy and during treatment of patients with VAP; significant decrease of pathogens is represented on the $7^{\text {th }}$ day $(p<0.01)$.

times. The values of microorganisms in the investigated material did not exceed the critical-permissible level of microbial loading, which is in decimal logarithm consisting of $4 \mathrm{CFU} / \mathrm{mL}$. The main group of VAP-causing pathogens were not determined in the sputum from most of the patients after 14 days of therapy (Figure 5).

In patients of the comparison group, i.e. who received only standard systemic antibiotic therapy, higher rates of microbial airway colonization were observed during the 1 st week of treatment. On the $7^{\text {th }}$ day, the number of opportunistic pathogens that were determined in these patients with VAP reached log $(6.49 \pm 0.35) \mathrm{CFU} / \mathrm{mL}$, exceeding by 4 orders of magnitude the amount of microorganisms in the inflammation locus in patients of the observation group $(\mathrm{p}<0.001)$.

\section{TLR-4 assessment}

A significant decrease in the microbial count in the tracheobronchial secretion of patients in the comparison group was observed only after 10 days of systemic antibiotic therapy $(\mathrm{p}<0.001)$. The total microbial count was expressed in log in $1 \mathrm{ml}$ of tracheobronchial secretion. After 14 days of treatment, there was about a 2 -fold decrease in total microbial count, in comparison with the $7^{\text {th }}$ day data, and amounted to $3.44 \pm 0.23 \mathrm{CFU} / \mathrm{mL}$, which exceeded this indicator in the study group by 13 -fold.
A smaller increase in serum TLR-4 levels in the early period of treatment was observed in patients who received inhalations of decamethoxine. Indeed, TLR4 level was noted to be 1.42 times lower in patients of the study group on the 3rd day after treatment, when compared to the comparison group ( $p<0.001$;

\section{(Figure 6).}

A significant increase (by 1.7 fold) of serum TLR4 level $(\mathrm{p}<0.001)$ was detected together with an increase in colonization rates by gram-negative bacteria in the tracheobronchial aspirate on the $3^{\text {rd }}$ day (rPearson=0.880) in the comparison group.

The positive dynamics of the microbial count in the aspirates obtained from the patients in the main group were accompanied by the decrease in TLR- 4 level after the $7^{\text {th }}$ day of treatment. A strong correlation between the reduction of gram-negative pathogens of respiratory infections and the decrease of TLR- 4 levels, compared to baseline indices ( $r$-Pearson=0.893), has been established as proof of the efficacy of the additional application of DCM in the complex treatment of patients with VAP. In comparison, TLR4 serum levels in VAP patients receiving only systemic therapy remained two times higher $(\mathrm{p}<0.001)$ than that of the primary group, and correlated with an increased number of gram-negative microorganisms in the tracheobronchial aspirates of patients ( $r-$ Pearson=0.801). 


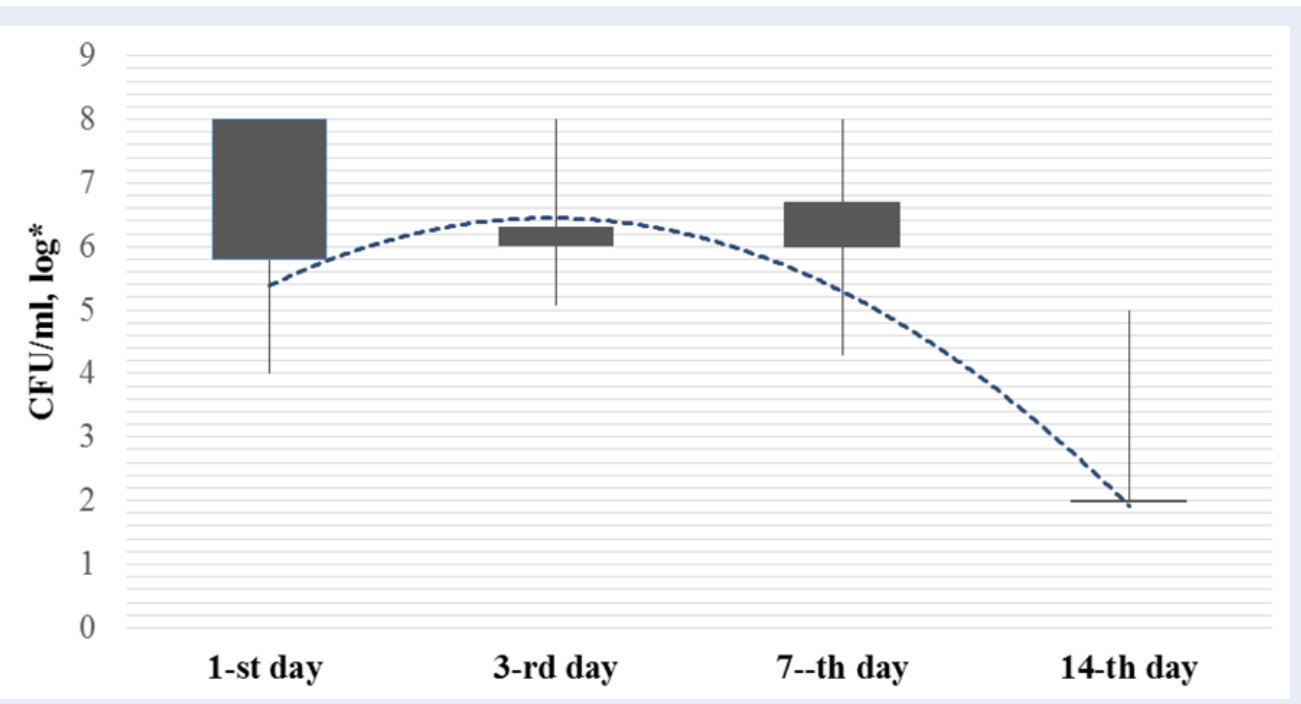

Figure 5: Microbial colonization of airways in patients with VAP in the comparison group. *: average values of the total number of microorganisms in $1 \mathrm{~mL}$ of tracheobronchial aspirates expressed in log (CFU/mL). Average number of microorganisms in $1 \mathrm{~mL}$ of tracheobronchial aspirates expressed in log $(\mathrm{CFU} / \mathrm{mL})$ from the beginning of antimicrobial therapy and during treatment; in significant difference of average values is present after the $3^{r d}$ and $7^{\text {th }}$ day $(p>0.05)$ of antimicrobial treatment.

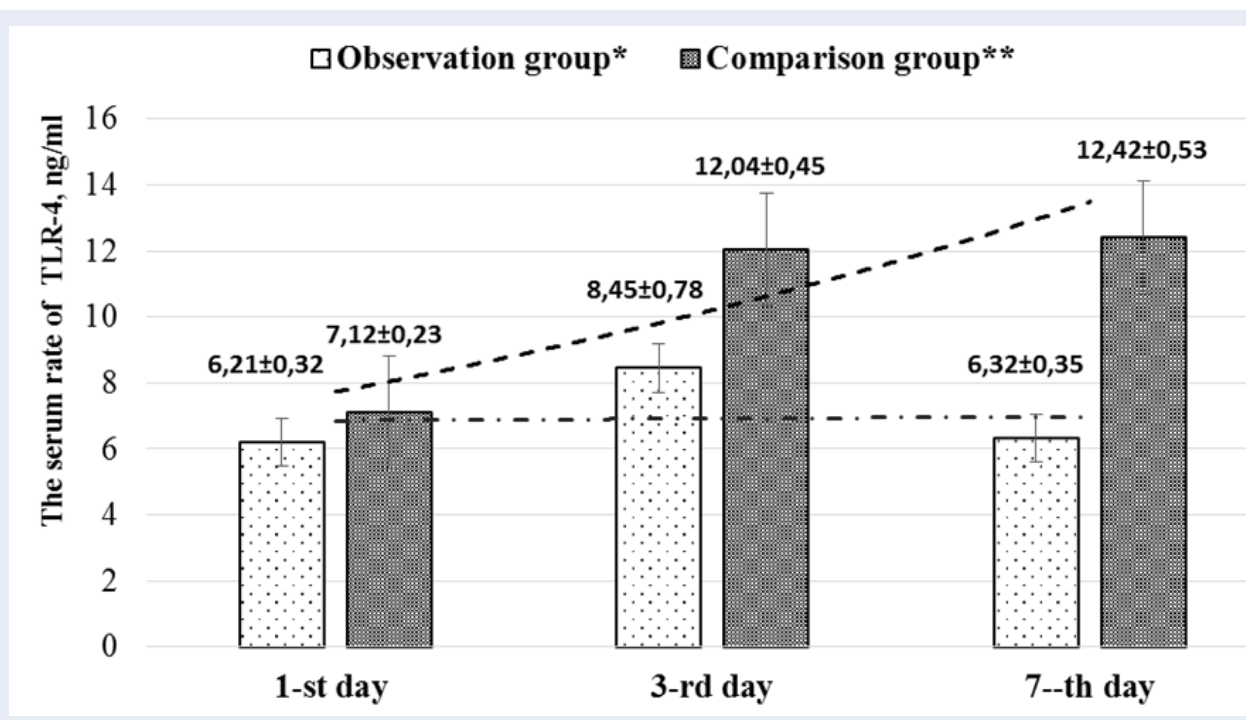

Figure 6: The rates of TLR-4 in serum of patients with VAP (in $\mathbf{n g} / \mathbf{m L}$ ). Columns demonstrate the in significant difference of TLR-4 levels at the beginning of antimicrobial treatment in both groups (the $1^{\text {st }}$ day $-p>0.05$ ) and show rapid significant increase of serum TLR-4 concentrations when only systemic antibiotics were used during therapy course (on the $3^{r d}$ day $-p<0.01$ and on the $7^{\text {th }}$ day $-\mathrm{p}<0.001$ ). 


\section{DISCUSSION}

From a microbiological point of view, it is well-known that VAP, which occurs after 96 hours of mechanical ventilation (late-onset VAP), is usually caused by antibiotic-resistant bacteria and requires rapid initiation of broad-spectrum antibacterial therapy. However, recent data suggests that in the vast majority of cases, the infection in patients with early VAP onset is caused by a nosocomial microflora. In this case, infectious complications are usually caused by bacteria, resistant to antimicrobial agents ${ }^{9-11,26}$.

According to the results of our study, it was found that the spectrum of pathogens in patients with VAP, at the onset of the disease, is predominantly represented by gram-positive and gram-negative bacteria. As well, there is representation of a smaller number of yeastlike fungi of the genus Candida, S.aureus, S.pyogenes, A.baumannii, P.aeruginosa and K.pneumoniae which were isolated from patients even at the early manifestation of VAP. Candida colonized the respiratory tract of patients with VAP somewhat less frequently (10.2\%). Only in 1 of the patients was S. maltophilia identified in the monoculture and considered as the etiological agent of VAP. Indeed, the microbial spectrum of pathogens isolated from VAP patients was mostly well-known prominent microorganisms associated with this complication in critically ill children. According to some experimental and clinical trials, one of the most important points to emphasize is that among many kinds of antimicrobial therapy, administration of antimicrobial agents in inhalations by means of a nebulizer in patients undergoing MV is highly effective. The use of antimicrobial therapy through a nebulizer during MV ensures rapid direct delivery of a medicinal antimicrobial drug directly into the lung parenchyma, creating its high concentration directly at the site of the largest microbial colonization, which in turn leads to an effective rapid destruction of the VAP pathogens. Moreover, the inhalation administration of drugs reduces the risk of the potential systemic toxic effects of the drugs ${ }^{14-16}$. According to the results of our study's clinical observation, the inhalation use of an antiseptic based on DCM showed significant benefits in the treatment of severe patients with VAP. Clinical data of respiratory functions showed that in the group of patients who received only standard systemic antibiotic therapy (without DCM use) during 48-72 hours of MV, a gradual decrease of dynamic complication (by 3.4fold) and resistance (by 2.4-fold) were determined, when compared to the group of patients who used DCM $(p<0.05)$. This is in line with the findings of the high efficiency of inhalation use of DCM in the complex treatment of respiratory infections as demonstrated by other researchers ${ }^{21}$.

Our study show that patients with VAP who received inhalation of quaternary ammonium antiseptic decamethoxine in the complex management of respiratory infectious complications, had a significant decrease in microbial colonization. Meanwhile, for patients receiving only standard systemic antibiotic therapy, higher rates of airway colonization by opportunistic microorganisms were observed during the $1^{\text {st }}$ week of treatment. On the $7^{\text {th }}$ day, the quantitative content of pathogens in the respiratory tract of patients in the comparison group exceeded (by four orders of magnitude) the number of microorganisms in situ in inflammation of patients who additionally received nebulizer therapy with DCM $(\mathrm{p}<0.001)$.

According to our findings, the advantages of additional inhalation management with DCM in the enhancement of microbial eradication and normalization of some factors of innate immune response in patients with VAP have been demonstrated. Our results revealed that respondents who received inhalations of DCM antiseptic drug for 7 days had a decrease of the microbial count in the tracheobronchial secretion, which was accompanied by a decrease of nonspecific immune response factor levels (TLR-4). The occurrence was mediated and maintained by gram-negative bacteria persistence. Consistent with the analysis of current studies, which suggest a strong correlation between the decrease of TLR- 4 serum concentrations and colonization degree by gram-negative microorganisms in the respiratory tract of patients in the observation group ( $r$-Pearson=0.801), the DCM administration led to an early recovery period of patients with VAP.

The conducted clinical and microbiological study herein, of the effectiveness of inhalation use of an DCM-based antiseptic drug in the complex treatment of VAP, showed an early decrease in the absolute number of opportunistic pathogens in the respiratory tract. Moreover, their rapid eradication, minimal changes and rapid recovery of respiratory parameters after mechanical ventilation corroborate the positive effect of DCM on the clinical course of VAP.

\section{CONCLUSIONS}

The most obvious finding to emerge from this study was that early inhalation of quaternary ammonium decamethoxine-based antiseptic drug Decasan , through a nebulizer during the first 7 days in complex antimicrobial therapy, provides gradual improvement (by 3.4-fold) of the dynamic compliece and a 2.4-fold 
reduction of lung resistance during 48-72 hours of mechanical ventilation. This was accompanied by effective early (on the $3^{\text {rd }}$ day) reduction of the absolute amount of microorganisms (by $10^{4}$-fold) in $1 \mathrm{ml}$ of tracheobronchial sputum, compared to that of the initial level of microbial colonization. Our findings demonstrate significant qualitative changes in the microbial spectrum, as characterized by prevalence of monoculture $(61.11 \%)$ on the $7^{t h}$ day, but not in microbial associations (93.33\%). There was an observed complete eradication of pathogens of infectious complications from the respiratory tract of patients after 14 days of management, in comparison with traditional treatment $(\mathrm{p}<0.001)$.

In summary, the decrease of gram-negative microorganism counts in the respiratory aspirates of patients with VAP (who received DCM inhalations) was accompanied by a slight increase of TLR- 4 serum level in the early period ( $3^{r d}$ day), and was closely correlated with a faster (1.42-fold) reduction of rate TLR4 levels to baseline on the $7^{\text {th }}$ day of treatment (rPearson=0.893). This confirm the positive influence of inhalation use of quaternary ammonium antiseptic on respiratory functions of critically ill children, as well as on the clinical course of VA in those patients.

\section{COMPETING INTERESTS}

The authors declare that they have no competing interests.

\section{AUTHORS' CONTRIBUTIONS}

NOA: made substantial contributions to conception and design, or acquisition of data, or analysis and interpretation of data; agreed to be accountable for all aspects of the work in ensuring that questions related to the accuracy or integrity of any part of the work are appropriately investigated and resolved involved in drafting the manuscript or revising it critically for important intellectual content.

DDV: made substantial contributions to conception and design, or acquisition of data, or analysis and interpretation of data; agreed to be accountable for all aspects of the work in ensuring that questions related to the accuracy or integrity of any part of the work are appropriately investigated and resolved involved in drafting the manuscript or revising it critically for important intellectual content.

DKD: made substantial contributions to conception and design, or acquisition of data, or analysis and interpretation of data; agreed to be accountable for all aspects of the work in ensuring that questions related to the accuracy or integrity of any part of the work are appropriately investigated and resolved involved in drafting the manuscript or revising it critically for important intellectual content.

\section{ABBREVIATIONS}

$\mathrm{C}_{d y n}$ - Dynamic compliance

CDC - Centers for Disease Control and Prevention

CFU - Colony-forming unit

DCM - Decamethoxine

ICU - Intensive care unit

LLC — Limited Liability Company

MV - Mechanical ventilation

NNIS - National Nosocomial Infection Surveillance

PEEP - Positive end-expiratory pressure

PIP - Peak inspiratory pressure

QACs - Quaternary ammonium compounds

TLR - Toll-like receptors

US - Ultra sound

VAP - Ventilator-associated pneumonia

\section{REFERENCES}

1. Shahin J, Bielinski M, Guichon C, Flemming C, Kristof AS. Suspected ventilator-associated respiratory infection in severely ill patients: a prospective observational study. Critical Care (London, England). 2013;17:R251. Available from: DOI:10. 1186/cc13077.

2. Joseph NM, Sistla S, Dutta TK, Badhe AS, Parija SC. Ventilatorassociated pneumonia: a review. European Journal of Internal Medicine. 2010;21:360-8. Available from: DOI:10.1016/j.ejim. 2010.07.006.

3. Rea-Neto A, Youssef NC, Tuche F, Brunkhorst F, Ranieri VM, Reinhart K. Diagnosis of ventilator-associated pneumonia: a systematic review of the literature. Critical Care (London, England). 2008;12:R56. Available from: DOI:10.1186/cc6877.

4. Kollef $\mathrm{MH}$, Hamilton CW, Ernst FR. Economic impact of ventilator-associated pneumonia in a large matched cohort. Infection Control and Hospital Epidemiology. 2012;33:250-6. Available from: Doi:10.1086/664049.

5. Melsen WG, Rovers MM, Groenwold RH, Bergmans DC, Camus C, Bauer TT. Attributable mortality of ventilator-associated pneumonia: a meta-analysis of individual patient data from randomised prevention studies. The Lancet Infectious Diseases. 2013;13:665-71. Available from: Doi:10.1016/s14733099(13)70081-1.

6. Elliott D, Elliott R, Burrell A, Harrigan P, Murgo M, Rolls K. Incidence of ventilator-associated pneumonia in Australasian intensive care units: use of a consensus-developed clinical surveillance checklist in a multisite prospective audit. BMJ Open. 2015;5:e008924. Available from: DOI:10.1136/ bmjopen-2015-008924.

7. Gupta A, Agrawal A, Mehrotra S, Singh A, Malik S, Khanna A. Incidence, risk stratification, antibiogram of pathogens isolated and clinical outcome of ventilator associated pneumonia. Indian Journal of Critical Care Medicine : PeerReviewed, Official Publication of Indian Society of Critical Care Medicine. 2011;15:96-101. Available from: Doi:10.4103/09725229.83015.

8. Edwards JR, Peterson KD, Mu Y, Banerjee S, Allen-Bridson K, Morrell G. National Healthcare Safety Network (NHSN) report: data summary for 2006 through 2008, issued December 2009. American Journal of Infection Control. 2009;37:783805. Available from: DOI:10.1016/j.ajic.2009.10.001. 
9. Pasquale MD, Ferrer M, Esperatti M, Crisafulli E, Giunta V, Bassi GL. Assessment of severity of ICU-acquired pneumonia and association with etiology. Critical Care Medicine. 2014;42:303-12. Available from: DOI:10.1097/ CCM.0b013e3182a272a2.

10. Park DR. The microbiology of ventilator-associated pneumonia. Respiratory Care. 2005;50:742-63.

11. Thoracic SA, of AIDS. Guidelines for the management of adults with hospital-acquired, ventilator-associated, and healthcareassociated pneumonia. American Journal of Respiratory and Critical Care Medicine. 2005;171:388-416. Available from: DOI:10.1164/rccm.200405-644ST.

12. Russell CJ, Shiroishi MS, Siantz E, Wu BW, Patino CM. The use of inhaled antibiotic therapy in the treatment of ventilatorassociated pneumonia and tracheobronchitis: a systematic review. BMC Pulmonary Medicine. 2016;16:40. Available from: DOI:10.1186/s12890-016-0202-8.

13. Abu-Salah T, Dhand R. Inhaled antibiotic therapy for ventilator-associated tracheobronchitis and ventilator-associated pneumonia: an update. Advances in Therapy. 2011;28:728-47. Available from: DOI:10.1007/s12325-011-0051-z.

14. Ehrmann S, Chastre J, Diot P, Lu Q. Nebulized antibiotics in mechanically ventilated patients: a challenge for translational research from technology to clinical care. Annals of Intensive Care. 2017;7:78. Available from: DOI:10.1186/s13613017-0301-6.

15. Lu Q, Luo R, Bodin L, Yang J, Zahr N, Aubry A, et al. Efficacy of high-dose nebulized colistin in ventilator-associated pneumonia caused by multidrug-resistant Pseudomonas aeruginosa and Acinetobacter baumannii. Anesthesiology. 2012;117:1335-47. Available from: DOI:10.1097/ALN. 0b013e31827515de.

16. Burnham JP, Kollef MH. Prevention of Staphylococcus aureus Ventilator-Associated Pneumonia: Conventional Antibiotics Wont区ut It. Clinical Infectious Diseases. 2017;64:108991. Available from: DOI:10.1093/cid/cix060.

17. Zhang TT, Tang SS, Fu LJ. The effectiveness of different concentrations of chlorhexidine for prevention of ventilatorassociated pneumonia: a meta-analysis. Journal of Clinical Nursing. 2014;23:1461-75. Available from: DOI:10.1111/jocn. 12312.

18. Labeau SO, de Vyver KV, Brusselaers N, Vogelaers D, Blot SI. Prevention of ventilator-associated pneumonia with oral antiseptics: a systematic review and meta-analysis. The Lancet infectious diseases. 2011;11:845-854.

19. Tsarev AV. Effect of oropharyngeal decontamination by dekasan for the prevention of ventilator-associated pneumonia in critically ill patients. Emergency Medicine. 2016;5:5761. Available from: Doi:10.22141/2224-0586.5.76.2016.76435.

20. Shkurupiy DA, Bieliaiev S. Sanitation of oral cavity - option for prevent ion of ventilator-associated pneumonia in newborns. Biomedical and biosocial anthropology. 2016;(26):143-146. Available from: http://nbuv.gov.ua/UJRN/bba_2016_26_40.

21. Gumeniuk M, Panchuk S. Decametoxine influence on bronchial hyperreactivity in patients with bronchial asthma. European Respiratory Journal. 2014;44:P1832.

22. Horan TC, Andrus M, Dudeck MA. CDC/NHSN surveillance definition of health care-associated infection and criteria for specific types of infections in the acute care setting. American Journal of Infection Control. 2008;36:309-32. Available from: DOI:10.1016/j.ajic.2008.03.002.

23. Foglia E, Meier MD, Elward A. Ventilator-associated pneumonia in neonatal and pediatric intensive care unit patients. Clinical Microbiology Reviews. 2007;20:409-25. Available from: Doi:10.1128/cmr.00041-06.

24. Fine MJ, Auble TE, Yealy DM, Hanusa BH, Weissfeld LA, Singer $D E$, et al. A prediction rule to identify low-risk patients with community-acquired pneumonia. New England journal of medicine. 1997;336(4):243-250.

25. M CE. Toll-Like Receptors: Methods and Protocols. In: Toll-Like Receptors: Methods and Protocols; 2016. p. 455. null.

26. Combes A, Luyt CE, Trouillet JL, Chastre J. Controversies in ventilator-associated pneumonia. Seminars in Respiratory and Critical Care Medicine. 2010;31:47-54. Available from: DOI:10.1055/s-0029-1246288.

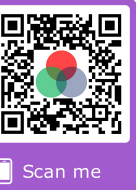

